\title{
Associated Factors of Caesarean Section in Ethiopia Using 2016 Demographic Health Survey Data; Community Based Cross Sectional Study
}

\author{
Abebaw Gedef Azene ( $\nabla$ abebaw2516@gmail.com ) \\ Debre Markos University College of Natural and Computational Science \\ Abiba Mihret Aragaw \\ Debre Markos University College of Natural and Computational Science \\ Mihretie Gedefaw \\ Debre Markos University College of Health Science
}

\section{Research article}

Keywords: Caesarean section, multilevel logistics, demographic health, Ethiopia

Posted Date: September 27th, 2019

DOI: https://doi.org/10.21203/rs.2.15260/v1

License: (c) (i) This work is licensed under a Creative Commons Attribution 4.0 International License. Read Full License 


\section{Abstract}

Background In Ethiopia, caesarean section delivery has become a popular method preferred by mothers and husbands recently. Identifying associated demographic health factors to increase the rate of caesarean section is desirable in Ethiopia.Methods Community based cross-sectional study design was conducted among women in the reproductive age group (age 15-49) in Ethiopia. The analysis was based on data from mothers who had given at least one birth during the five years preceding the survey. The data are accessed from 2016 Ethiopian Demographic Health Survey. The study was applied multilevel logistics regression model.Results Mothers were urban residence more undergoing to $\mathrm{C}$-section than those rural. More educated mothers were more delivering with $\mathrm{C}$-section compared with those illiterate. A mother had multiple pregnancy more delivering with $c$-section than those single pregnancy $(p=0.0001)$. A mother had been higher body mass index were more likely to delivering with caesarean section than those smaller body mass index $(p=0.0001)$. Caesarean section was increased when mothers goes to elder $(p=$ 0.0001).Conclusions The finding of this study was mothers education level, Birth order, preceding birth interval, multiple pregnancy, maternal age and interaction effect BMI with household wealth index was statistically significant associated factors to increase rate of caesarean section. Residence and region was community level factors to increase caesarean section delivery. Therefore; community awareness and perception creation towards caesarean section with its side effect is essential in Ethiopia.

\section{Introduction}

Caesarean section has more preferring by mothers in the world lately. Caesarean section improves infant and/or maternal outcomes. However, when used inappropriately the potential injury may exceed the benefit $(1,2)$.

The major risks of caesarean section delivery on mothers are: postpartum morbidity, reduced fertility, infection, thromboembolic disorders and abnormal placentation in future pregnancies (3). In addition to mothers, c-sec[1]tion has risk on their child. These risks are associated with postpartum respiratory morbidity, less breastfeeding, possibly more atopic disease, iatrogenic prematurity and birth trauma $(4,5)$.

C-section has a modest risk factor for respiratory distress syndrome, particularly if the csection was performed in a non-laboring woman (6). C-section is more expense than vaginal delivery and increased risks to mother and baby despite of the fact that the rate of c-section is still increasing. C-section is international concern to prevent its risk until now(7).

The rate of c-section has been increasing in the world due to health demographic factors (8). Different studies show that this rate was varied from $26 \%$ up to $60 \%$ in comparison with some 
private institute which was up to $87 \%$ (9) While the rate ranges between 12 and $86 \%$ across studies done in developed countries and in developing countries vary between 2 and 39 \% (10, 11). However, WHO suggested, the incidence should be less than $15 \%$ of total deliveries (12). Lately, C-section is increasing in Ethiopia because of the improvement of obstetric care service in the country (10). In the urbanized area, the rate ranges from 8 to $37 \%(10,13)$.

Due to the fact that many factors have been proposed for the increment in c-section rate across the world. Multiple pregnancy and breech presentation was the primary cause of the increment of of c-section. Some others study revealed that it is associated with maternal preferences and maternal age $(10,14)$. Few studies showed that, birth weight, birth order, maternal height and history of antenatal care visit (ANC) to be factors associated with caesarean section (15).

Little information is available on health and demographic factors to increase the rate of caesarean section in Ethiopia. Therefore; This study intended to assess associated health and demographic factors lead to c-section and contributes additional information about the its deliveries. This research will be vital to provide some input for other researchers to conduct and detailed study.

* corresponding author; Email: abebaw2516@gmail.com. Author(s) agree that this article remain permanently open access under the terms of the Creative Commons Attribution License 4.0 International License

\section{Methods}

Study Design and Setting

Community based cross- sectional study design was conducted using 2016 Ethiopian Health and Demographic Survey data collected from January 18 to June 27, 2016. The survey was designed to provide information for the health and demographic variables of interest in the country. Multi-stage sampling was applied. The data were collected from each selected household in the selected enumeration area using structured and unstructured questionnaires. 
Specific questions were asked a woman about their pregnancy and birth in the five years preceding the survey. The selected 7,193 women (age 15-49) had at least one birth in the last five years prior to the survey were eligible for the study. The 2016 EDHS data set has a hierarchical structure as women are nested within geographic regions and residence. The hierarchy for this study follows individuals as level-1, regions as and residence as level-2.

\section{Inclusion and Exclusion Criteria}

The study included a woman's who give birth within five years to the study either by c-section or vaginal delivery who were considered during the 2016 EDHS survey. The study excluded a woman had given birth before five years a survey conducted.

\section{Variables}

Dependent Variable: The dependent variable of this study was mode of delivery. It was dichotomies categorized as vaginal deliveries and caesarean deliveries ( 0 is coded for the vaginal deliveries and 1 is for the caesarean section delivery).

Explanatory Variable: The explanatory variables were region, residence, religion, maternal age, BMIs of woman, women's education level, household wealth index, birth order, preceding birth interval, terminated pregnancy ever, number of antenatal visits, contraceptive use before pregnancy, anaemic level of women, multiple pregnancy, drug take for intestinal disease, sex of the child.

Statistical Analysis and Model

In this study both descriptive and inferential statistical methods were used to analyse. In analysing, bivariate and multivariable analyses were employed. The bivariate analysis was applied to examine the association between each of the independent variables and c-section. The multilevel logistics model was applied to comprehend community variation and identifying individual level health and demographic factors associated with c-section, which is a hierarchical generalized linear model by introducing random and fixed component simultaneously. The parameters obtained using multilevel logistic regression packages using 
R statistical software. The coefficients of the predictor variables were estimated by maximum likelihood estimation $(16,17)$. For model comparison, log likelihood and AIC was applied.

\section{Result}

A total of 7193 mothers were eligible. Out of these mothers 256 were delivered by CS. Six hundred thirty seven (8.85\%) mothers had previous history of terminated pregnancy. Among these mothers, 31 (4.87\%) had delivered by CS.

Of the 256 mothers, most of them were 54.29\% orthodox Cristian, 33.20\% were primary school educated, $28.52 \%$ were higher educated, $78.13 \%$ were from richest households, 99.22\% were not smoked, $12.11 \%$ had been previous history of terminated pregnancy, 54.69\% were given male babies, $9.37 \%$ had taken the drug for intestinal disease, $51.95 \%$ had used modern contraceptive method, $93.75 \%$ had multiple pregnancy, and $77.73 \%$ had not infected by anaemic.

Among 256 mother was delivered by c-section, the average birth order of the mothers getting the child was 2.31 ( $\mathrm{SD}=1.83$ ); preceding birth interval of mothers had been getting birth were 60.51 months with standard deviation 4.98 month; ANC of mothers during pregnancy period was 5.59 (SD 3.25,); the average maternal age was 30.08 years ( $S D=5.94$,); and body max index of mothers were 20.81 $(\mathrm{SD}=3.43)$. (See Table 1).

Looking mothers had been delivered by CS regarding community factors, $11.2 \%$ were residing in Harerri region, 21.9\% were in Addis Abeba, and 12.7\% were from urban areas. (See Table 1 in the appendix and Table 2).

Among 6937 vaginal delivered mothers, 4317 (62.23\%)were not educated, 2411 (34.76\%) were poorest household, 6331 (91.26\%) hadn't previous history of terminated pregnancy, 459 (6.62\%) had taken drugs for intestinal disease during pregnancy. The average ANC of mothers were 2.78(SD. 5.56), BMIs 20.68(SD. 3.29).

\section{Bivariable analysis of factors with CS delivery}

Bivariate analysis of factors associated with CS and covariates considered in this study for individual and community factors was presented in Table 1 in appendix and Table 2. 
There was association between c-section and covariates religion, maternal education, household wealth index, terminated pregnancy ever, contraceptive use, multiple pregnancies, the anaemic status of a woman, ANC, birth order, preceding birth interval, maternal age and BMIs in level-1, and region and residence at level-2. The remaining variables were not associated with the c-section at the $10 \%$ level of significance.(See Table 1 in the appendix and Table 2).

\section{Multivarable multilevel logistic regression analysis of c-section}

The measure of association and random intercepts for c-section are presented in appendix

Table 2 Bivariate analysis of the association between community level factors with c-section method, EDHS 2016

\begin{tabular}{|c|c|c|c|}
\hline Covariates & Caesarean section $\mathbf{n}(\%)$ & All vaginal births $n(\%)$ & p-value \\
\hline Region & & & $<.0001$ \\
\hline Tigray & $21(2.7)$ & $751(97.3)$ & \\
\hline Afar & $6(0.9)$ & $641(99.1)$ & \\
\hline Amhara & $16(2.1)$ & $748(97.9)$ & \\
\hline Oromia & $14(1.4)$ & 1017(98.6) & \\
\hline Somali & $5(0.6)$ & $801(99.4)$ & \\
\hline Benshangul & $6(1)$ & $570(99.0)$ & \\
\hline SNNP & $23(2.6)$ & $870(97.4)$ & \\
\hline Gambella & $6(1.1)$ & $528(98.9)$ & \\
\hline Harari & $46(11.2)$ & $365(88.8)$ & \\
\hline Addis Abeba & $82(21.9)$ & $293(78.1)$ & \\
\hline Dire Dewa & $31(8.1)$ & $353(91.9)$ & \\
\hline Residence & & & 0.000 \\
\hline Urban & $192(75)$ & $1320(19.03)$ & \\
\hline Rural & $64(25)$ & $5617(80.97)$ & \\
\hline
\end{tabular}

Table 3. The results of the empty model (Model 1) indicated that there was a statistically significant variation in the odds of delivery method between communities (random intercept 
variance $=1.064, \mathrm{p}$-value $=0.000$ )

Similarly, the ICC in the empty model implied that $24.44 \%$ of the total variance in the delivery method was credited to differences between communities.

In Model 2 only level-1 variables were added. From its results, maternal education level, birth order, preceding birth interval, multiple pregnancy, maternal age, household wealth index and interaction effects of body max index of woman with household wealth index were significantly associated with caesarean section delivery method. The ICC in Model 2 indicated that, $23.79 \%$ of the variation in delivery method were accountable to differences across communities. As shown by the PCV, 3.5\% of the variance in caesarean section delivery method across communities was explained by the individual level characteristics.

Model 3 only community level variables were added. The result revealed that woman residing in communities from rural area and from regions Somali, Gammbella, Harreri, Addis Abeba and Dire Dewawere significantly associated with c-section. The ICC in Model 3 showed that differences between communities account $23.98 \%$ of the variation in woman caesarean section. In addition, the PCV indicated that $2.4 \%$ of the variation in caesarean delivery method communities was explained by community level characteristics.

Model 4, the final model included both level-1 and level-2 characteristics simultaneously using stepwise variable selection which have p-value less than 0.1 from the bivariate analysis. The estimated ICC, $23.48 \%$ of the variability in c-section was accountable to differences between communities. The PCV indicated that, $5.1 \%$ of the variation in caesarean section delivery across communities was explained by both individual and community level factors included in model 4. After adjusting other individual and community level factors. Covariates; maternal education, birth order, preceding birth interval, multiple pregnancy, maternal age, household index and interaction effects of BMIs and household wealth index in level-1 and residence, region (Gambella, Hareri, Addis Abeba and Dire Dewa) in level-2 factors were significantly associated with caesarean section.

The odds of undergoing caesarean section was $2 \%(\mathrm{AOR}=1.02,95 \%$ CI $0.96-1.027), 3 \%$ $(\mathrm{AOR}=1.03 ; 95 \%$ CI 1.02-1.05) and 14\% (AOR 1.14; 95\% CI 1.11-1.16) more likely a mother had primary education, secondary education and higher education compared to woman who 
hadn't educated. The odds of experiencing caesarean section were 1.7\% (AOR=0.993; 95\% CI 0.99-0.995) less likely if a mother having one birth order increased. Similarly, mothers having more preceding birth interval was 1.0005 (AOR=1.0005; 95\% CI 1.0003, 1.001) times more likely to deliver by caesarean section.

Regarding the woman having multiple pregnancy was $12 \%$ (AOR=1.12; 95\% CI 1.08-1.15) more likely to give birth by caesarean section. Likewise, a woman becoming older was 1.0920 (AOR=1.092; 95\% CI 1.055, 1.130) times more likely to deliver by c-section as compared to younger. The odds of delivered by caesarean section of a woman from the richest households were $22 \%(\mathrm{AOR}=0.78 ; 95 \%$ CI $0.73-0.48)$ smaller than as compared to women from the poorest households. For one unit increased of BMIs, the odds, giving birth by caesarean section was $1 \% \quad(\mathrm{AOR}=1.01 ; 95 \%$ CI 1.008-1.02) higher among a woman from the richest household.

Similarly a woman in rural residence was $2 \%(\mathrm{AOR}=0.98 ; 95 \%$ CI $0.96-0.998)$ less likely to give birth by caesarean section delivery compared to their urban counterparts. Looking Region, women residing in communities from Gambella had 2\% smaller (AOR=0.98; 95\% CI 0.96-99), Harri had 7\% higher (AOR $=1.07 ; 95 \%$ CI 1.05-1.09), Addis Abeba had 10\% higher $(\mathrm{AOR}=1.1,95 \%$ CI 1.06-1.12) and Diere Dewa had 4\% higher (AOR=1.04, 95\% CI 1.01-1.06) were likely of delivery by caesarean section as compared to women residing in communities from Tigray. See Table 3 in the Appendix.

\section{Discussion}

Community based cross- sectional study design was conducted using 2016 Ethiopian Demographic and health Survey data collected from January 18 to June 27, 2016. The aim of the study was to identify associated health and demographic factors of c-section.

The findings of this study showed that woman's had more educated, more likely to deliver by c-section. This result agreed with findings inside and outside the country $(1,18,19)$.

The possible reasons could be, educated woman's might search a means to minimize absorbate. Educated woman's had more worry their health and they have taken action to prove their health. In addition to this, educated mothers have greater confidence to give birth by caesarean section. 
The odds of mothers who had delivered by c-section were less likely for one birth order increase. The findings consistent with studies conducted at the Felege Hiwot Referral Hospital, Bahir Dar (18). The possible explanation could be mothers had more birth order, prepare themselves by feeding balanced foods which used to minimize labour and the uterus easily opening during labour due to the experience of birth. In addition to this woman who had done easy tasks which have no impact on pregnancy based on previous experience.

The study showed that mothers had more proceeding birth interval, more likely undergoing to c-section. This finding was agreed with another study in the country and outside the country $(13,20)$. The reason could be mothers who had more preceding birth interval; the uterus will not open easily so it prolong absorbate.

The study also revealed that mothers had faced multiple pregnancies was more likely to deliver by c-section than these faced single pregnancies. This finding was agreed with other studies done in the country and other developing countries $(18,19,21)$. The explanation could be mothers had faced multiple pregnancies were more complication sensitive and seek skilled care services for the fear of labour. Mother's decides that getting births by C-section is reduce absorbate and increase the health of the new birth babies during labour.

Surprisingly, the findings revealed that the number of ANC had not statistically significant effect on c-section in this study. The results consistent the study conducted in Wolayta Sodo $(19,21)$. The reasons could be women's follow ANC, they were well informed about the complication and the symptoms of pregnancy, and they may take remedial action. They manage nutrition style and prepare themselves for the delivery method which decreases labour if they start ANC earlier. ANC with skilled providers is one of the proven interventions that reduce maternal mortality by allowing early detection of obstetric complications and giving opportunity in influencing the woman's decision to choose a c-section.

The study revealed that maternal age had been increased by one year, mothers had most likely undergoing to caesarean section method.

This finding was agreed with other study outside the country $(10,13,18,22)$.The explanation could be woman who had more age, their body not flexible to birth and they had prolong absorbate due to pregnancy complication of age increment; the uterus was not opened easily. 
In this study, the anaemic status of women was not statistically significant factor of a woman who had undergoing c-section delivery. The reasons could be during ANC follow up, they have taken iron deficiency tablets for diagnosis of anemia if they were infected.

The findings of this study verified that women from the richest households had smaller odds of delivery by c-section for a unit increment of body mass index. This is consistent with the findings that have been reported in prior studies (19). The possible explanation could be related governmental health institution does not allow mothers delivered by c-section without medical implications. In addition, mothers from richest household having access to get information from media compared than woman from poorest household. The interaction effect of household wealth index with BMIs was included the difference could be due to it.

In the study, mothers from rural residence had less likely to deliver by caesarean section than mothers from urban.

This finding was agreement with other studies done inside and outside the countries (19, 20, 23). This could be due to the fact that mothers from rural residence having less chance to access hospitals, ANC and they have no confidence to give birth by c-section. In addition to this, most woman from a rural residence were poor, both economically and information to get access about c-section than woman from urban. Again, this was inconsistent with the study conducted at the Felege Hiwot referral hospital, Bahir Dar $(19,22)$. This variation was occurring due to the study area difference. They considered only referred woman's who had treated only in the hospital.

Similarly, the chance of mothers undergoing to c-section from Gambella was less likely than mothers from Tigray region, but the chance of mothers undergoing to c-section from Harerri, Addis Abeba, and Diere Dewa was higher than mothers from Tigray region. The findings consistent with the studies conducted in Ethiopia (19). This observation may be the access of getting health institutions in the region.

\section{Conclusions}

The findings of this study showed that health and demographic factors associated with mothers who had delivered with caesarean section was an education level of mothers, Birth order, multiple pregnancy, preceding birth interval, maternal age, household wealth index 
and interactions of household wealth index with BMIs in individual level. Residence and region were statistically significant community level factors associated with caesarean section. There was the variety of c-section in community level factors residence and regions in Ethiopia. As a recommendation, community awareness and the perception creation towards, side effects of caesarean delivery need to be enhanced. Encouraging mothers to have frequent ANC visits are also important to enhance awareness of caesarean section. The health center should be creating awareness about the association between contraceptive methods and delivery method.

\section{Limitations Of The Study}

The study was used secondary data suffer from missing values and unreliable information. Use of primary data which is collected the immediate users is preferable to minimize missing values and access medical (obstetric) indicator factors. The woman who answers their question as much as

they remember it since EDHS was used retrospective design so the respondent's may answer usually underestimate in socio- demographic factors and overestimate health related factors.

Therefore, the use of this information for comparison and decision-making should consider the inherent limitation of the study.

\section{Abbreviations}

$\mathrm{ANC}=$ antenatal care

EDHS $=$ Ethiopian demographic health survey

DHS $=$ Demographic health survey

$\mathrm{CS}=$ Caesarean section

$\mathrm{EA}=$ Enumerate Area

$\mathrm{sd}=$ Standard deviation 


\section{Declarations}

\section{Ethics approval and consent to participate}

Not Applicable.

The researcher have taken the data from the Ethiopian demographic, health survey and it was secondary. The researcher conducted this study in accordance with the guidelines laid down in the Declaration of Helsinki and all procedures involving human subjects. During the data collection, the participants were agreeing consent letter. For further information, contact the author.

\section{Consent for publication}

Not Applicable.

\section{Availability of data and materials}

The datasets used and/or analysed during the current study available from the corresponding author and EDHS 2016 on reasonable request.

\section{Funding}

Not applicable.

\section{Authors' contributions}

AGZ was responsible for the study design. AGA \& AMA contributed the statistical analyses and interpretation of the results. AGA \& MG drafted the manuscript and revised it critically and all authors approved the final version.

\section{Author's details}

${ }^{1}$ Department of Epidemiology and Biostatistics, Bahir Dar University, Bahir Dar, Ethiopia, ${ }^{2}$ Department of Statistics, Debre Markos University, Debre Markos, Ethiopia, ${ }^{3}$ Department of Nursing, Debre Markos University, Debre Markos, Ethiopia

\section{Competing interests}

The author declares that they have no competing interests. 
The authors would like to thank the study participants, data collectors, and CSA for giving the data and their support to finish the study.

\title{
References
}

\author{
Reference
}

1. Moosavi A, Sheikhlou SG, Sheikhlou SG, Abdolahi K, Yaminifar L, Maktabi M. Influencing factors in choosing delivery method: Iranian primiparous women's perspective. Electronic physician. 2017;9(4):4150.

2. Clark S, Taffeles S. Cesarean rate decreasing. Obstet Gynecol New. 1997;31(10).

3. Ananth CV, Smulian JC, Vintzileos AM. The association of placenta previa with history of cesarean delivery and abortion: a metaanalysis. American journal of obstetrics and gynecology. 1997;177(5):1071-8.

4. Dessole S, Cosmi E, Balata A, Uras L, Caserta D, Capobianco G, et al. Accidental fetal lacerations during cesarean delivery: experience in an Italian level III university hospital. American Journal of Obstetrics and Gynecology. 2004;191(5):1673-7.

5. Alexander JM, Leveno KJ, Hauth J, Landon MB, Thom E, Spong CY, et al. Fetal injury associated with cesarean delivery. Obstetrics \& Gynecology. 2006;108(4):885-90.

6. Gerten KA, Coonrod DV, Bay RC, Chambliss LR. Cesarean delivery and respiratory distress syndrome: does labor make a difference? American journal of obstetrics and gynecology. 2005;193(3):1061-4.

7. WAGAN F, MEMON GN. CHANGING TRENDS OF INDICATIONS AND RATE OF CESAREAN SECTION: AN AUDIT. Medical Channel. 2011;17(2).

8. Althabe F, Belizán JM. Caesarean section: the paradox. The Lancet. 2006;368(9546):14723.

9. Bani S, SEIED RA, SHAMSI GT, Ghojazadeh M, Hasanpoor S. Delivery Agents Preferences Regarding Mode of Delivery for Themslves and Pergnant Women (Obstetrics, Gynecologists, Midwives). 2010.

10. Abu Anza SH, Abu Omar AA. Frequency Rate and Indications of Cesarean Sections at Prince Zaid Bin Al Hussein Hospital-Jordan. Journal of the Royal Medical Services. 2012;19(1):82-6.

11. Organization WH, UNICEF. Monitoring emergency obstetric care: a handbook. 2009.

12. MOHAMMADI TS, KIANI AA, HEYDARI M. The survey on tendencies of primiparous women for selecting the mode of delivery. 2009.

13. Tsega F, Mengistie B, Dessie Y, Mengesha M. Prevalence of Cesarean Section in Urban Health Facilities and Associated Factors in Eastern Ethiopia: Hospital Based Cross 
Sectional Study. J Preg Child Health. 2015;2(3):169-73.

14. Kenny LC, Lavender T, McNamee R, O’Neill SM, Mills T, Khashan AS. Advanced maternal age and adverse pregnancy outcome: evidence from a large contemporary cohort. PloS one. 2013;8(2):e56583.

15. Thomas J, Paranjothy S. Royal College of Obstetricians and Gynaecologists Clinical Effectiveness Support Unit. National Sentinel Caesarean Section Audit Report. London: RCOG press; 2001.

16. Klein J, Moeschberger M. Survival analysis: techniques for censored and truncated data Springer-Verlag. New York, New York, USA. 1997.

17. Agresti A. An introduction to categorical data analysis, JohnWiley \& Sons. Inc, Publication. 1996.

18. Abebe FE, Gebeyehu AW, Kidane AN, Eyassu GA. Factors leading to cesarean section delivery at Felegehiwot referral hospital, Northwest Ethiopia: a retrospective record review. Reproductive health. 2016;13(1):6.

19. Mekonnen ZA, Lerebo WT, Gebrehiwot TG, Abadura SA. Multilevel analysis of individual and community level factors associated with institutional delivery in Ethiopia. BMC research notes. 2015;8(1):376.

20. Teguete I, Traore Y, Sissoko A, Djire M, Thera A, Dolo T, et al. Determining factors of cesarean delivery trends in developing countries: lessons from point G National Hospital (Bamako-Mali). Cesarean Delivery: InTech; 2012.

21. Hailemichael F, Woldie M, Tafese F. Predictors of institutional delivery in Sodo town, Southern Ethiopia. African Journal of Primary Health Care and Family Medicine. 2013;5(1):1-9.

22. Gutema H SA. cesarean section and associated factors at mizanaman general hospital, southwest Ethiopia. J Gynecol Obstet 2014;2(3):37- 41.

23. Rehan RSN, N. Prevalence and determinants of caesarean section in a teaching hospital of Pakistan. Journal of Obstetrics and Gynaecology. 2000;20(5):479-83.

\section{Tables}

Table 1 Bivariate analysis of associated factors at individual level demographic health variab] with c-section $\mathrm{N}=17193$ 


\begin{tabular}{|c|c|c|c|}
\hline \multirow{2}{*}{$\begin{array}{l}\text { Covariates } \\
\text { Religion }\end{array}$} & \multicolumn{3}{|c|}{$\begin{array}{l}\text { C-Section } n(\%) \text { All vaginal birth } n(\%) m e a n(s d p \text {-value } \\
\text { mean(sd) }\end{array}$} \\
\hline & & & 0.000 \\
\hline Orthodox \& Catholic & $139(54.29)$ & $2279(32.85)$ & \\
\hline Protestant & $42(16.41)$ & $1296(18.68)$ & \\
\hline Muslim & $74(28.90)$ & $3250(46.85)$ & \\
\hline Other & $1(0.39)$ & $112(1.61)$ & \\
\hline Education & & & 0.000 \\
\hline Not Educated & $42(16.41)$ & $4317(62.23)$ & \\
\hline Primary & $85(33.20)$ & $1857(26.77)$ & \\
\hline Secondary & $56(21.88)$ & $521(7.51)$ & \\
\hline Higher & $73(28.52)$ & $242(3.49)$ & \\
\hline Wealth index & & & 0.000 \\
\hline Poorest & $17(6.64)$ & $2411(34.76)$ & \\
\hline Poorer & $12(4.69)$ & $1167(16.82)$ & \\
\hline Middle & $13(5.07)$ & $1015(14.63)$ & \\
\hline Richer & $14(5.47)$ & $903(13.02)$ & \\
\hline Richest & $200(78.13)$ & $1441(20.77)$ & \\
\hline Smoking status & & & 0.719 \\
\hline No & $254(99.22)$ & $6867(98.99)$ & \\
\hline Yes & $2(0.78)$ & $70(1.01)$ & \\
\hline Sex of child & & & 0.328 \\
\hline Male & $140(54.69)$ & $3578(51.58)$ & \\
\hline Female & $116(45.31)$ & $3359(48.42)$ & \\
\hline Terminated pregnancy & & & 0.062 \\
\hline No & $225(87.89)$ & $6331(91.26)$ & \\
\hline Yes & $31(12.11)$ & $606(8.74)$ & \\
\hline Contraceptive Use & & & 0.000 \\
\hline Using modern Method & $133(51.95)$ & $1979(28.53)$ & \\
\hline Using Traditional Method & $10(3.91)$ & $37(0.53)$ & \\
\hline Non user intends to use later & $72(28.13)$ & $2042(29.44)$ & \\
\hline Does not intended to use & $41(16.02)$ & $2879(41.50)$ & \\
\hline Drugs take for intestinal diseas & & & 0.215 \\
\hline No & $232(90.63)$ & 6478(93.38) & \\
\hline Yes & $24(9.37)$ & $459(6.62)$ & \\
\hline Multiple Pregnancy & & & 0.000 \\
\hline Single & $240(93.75)$ & $6842(98.63)$ & \\
\hline Multiple & $16(6.25)$ & $160(1.37)$ & \\
\hline Anemia & & & 0.001 \\
\hline Sever & $2(0.78)$ & $117(1.69)$ & \\
\hline Moderate & $11(4.30)$ & $659(9.50)$ & \\
\hline
\end{tabular}




\begin{tabular}{llll} 
Mild & $44(17.19)$ & $1535(22.12)$ & \\
Not Anemic & $199(77.73)$ & $4626(66.69)$ & \\
Birth order & $2.31(1.83)$ & $3.98(2.56)$ & 0.000 \\
Preceding birth interval & $60.51(34.98)$ & $40.95(23.55)$ & 0.000 \\
ANC & $5.59(3.25)$ & $2.78(5.56)$ & 0.000 \\
Age & $30.08(5.94)$ & $29.23(6.87)$ & 0.000 \\
BMIs & $20.81(3.43)$ & $20.68(3.29)$ & 0.001 \\
\hline
\end{tabular}

Table.3 Multilevel logistic regression analysis of individual and community level demograpl health factors associated with c-section, 2016EDHS 


\begin{tabular}{|c|c|c|c|c|}
\hline Covariates & $\begin{array}{c}\text { Model } 1 \\
\text { AOR }(95 \% \mathrm{CI})\end{array}$ & $\begin{array}{c}\text { Model } 2 \\
\text { AOR }(95 \% \mathrm{CI})\end{array}$ & $\begin{array}{r}\text { Model } 3 \\
\text { AOR }(95 \% \mathrm{CI})\end{array}$ & $\begin{array}{c}\text { Model } 4 \\
\text { AOR }(95 \% \mathrm{CI})\end{array}$ \\
\hline Education level (Not Educated) & & 1 & & 1 \\
\hline Primary & & $1.02(1.01-1.03)^{*}$ & & $1.02(0.96-1.027)^{*}$ \\
\hline Secondary & & $1.04(1.01-1.05)^{*}$ & & $1.03(1.02-1.05)^{*}$ \\
\hline Higher & & $1.14(1.11-1.17)^{*}$ & & $1.14(1.11-1.16)^{*}$ \\
\hline Birth order & & $0.992(0.98-0.995)^{*}$ & & $0.993(0.99-0.995)^{*}$ \\
\hline Preceding birth interval & & $1.0005(1.0003-1.0007)^{3}$ & & $1.0005(1.0003-1.001)^{*}$ \\
\hline Child is twin (Single) & & 1 & & 1 \\
\hline Multiple & & $1.12(1.08-1.16)^{*}$ & & $1.12(1.08-1.15)^{*}$ \\
\hline Contraceptive (modern Method) & & 1 & & 1 \\
\hline Traditional Method & & $1.05(0.998-1.1)$ & & $1.05(0.99-1.105)$ \\
\hline Non user \&not use later & & $0.997(0.987-1.01)$ & & $0.998(0.98-1.009)$ \\
\hline Not intended use & & $0.989(0.97-1.001)$ & & $0.99(0.97-1.002)$ \\
\hline ANC & & $1.001(0.99-1.002)$ & & $1.001(0.999-1.002)$ \\
\hline Women Age & & $1.003(1.001-1.004)^{*}$ & & $1.003(1.002-1.004)^{*}$ \\
\hline Anemic Status (Sever) & & 1 & & 1 \\
\hline Moderate & & $0.994(0.96-1.03)$ & & $0.99(0.96-1.03)$ \\
\hline Mild & & 0.996(0.964-1.03) & & $0.99(0.96-1.03)$ \\
\hline Not Anemic & & $0.99(0.96-1.02)$ & & $0.99(0.961-1.024)$ \\
\hline BMIs & & $1.0003(0.997-1.003)$ & & $1.00(0.997-1.003)$ \\
\hline Household Wealth index (Poorest) & & 1 & & 1 \\
\hline Poorer & & $1.01(0.93-1.11)$ & & $1.013(0.93-1.11)$ \\
\hline Middle & & $0.99(0.89-1.09)$ & & $0.99(0.897-1.09)$ \\
\hline Richer & & $0.97(0.89-1.07)$ & & $0.97(0.88-1.07)$ \\
\hline Richest & & $0.79(0.74-0.85)^{*}$ & & $0.78(0.73-0.84)^{*}$ \\
\hline BMIs: household wealth index (Poorest) & & 1 & & 1 \\
\hline BMIs: Poorer & & 0.998(0.99-1.003) & & $0.99(0.99-1.003)$ \\
\hline BMIs: Middle & & $1.00(0.995-1.01)$ & & $0.99(0.99-1.01)$ \\
\hline BMIs: Richer & & $1.00(0.99-1.01)$ & & $1.001(0.996-1.005)$ \\
\hline BMIs: Richest & & $1.01(1.008-1.015)^{*}$ & & $1.01(1.008-1.02)^{*}$ \\
\hline Residance(Urban) & & & 1 & 1 \\
\hline Rural & & & $0.93(0.91-0.94) *$ & $0.98(0.96-0.998)^{*}$ \\
\hline Region (Tigray) & & & 1 & 1 \\
\hline Afar & & & $0.99(0.97-1.01)$ & $1.02(0.99-1.04)$ \\
\hline Amhara & & & $0.99(0.98-1.02)$ & $0.99(0.98-1.014)$ \\
\hline Oromia & & & $0.99(0.97-1.01)$ & $1.004(0.98-1.02)$ \\
\hline Somali & & & $0.98(0.96-0.99)^{*}$ & $1.01(0.99-1.02)$ \\
\hline Benshangul & & & $0.99(0.97-1.01)$ & $0.99(0.98-1.02)$ \\
\hline SNNP & & & $1.005(0.98-1.02)$ & $1.004(0.98-1.02)$ \\
\hline Gambella & & & $0.98(0.96-0.99) *$ & $0.98(0.96-0.99) *$ \\
\hline
\end{tabular}

Page $17 / 18$ 
Hareri

Addis Abeba

Dire Dewa

Communities variance(se)

ICC

PCV

Model fit

log likelihood

AIC
1.064(0.602)1.027(0.027)

$0.2444 \quad 0.2379$

Ref

$3.5 \%$

2169.56

2477.435

$-4333.119 \quad-4902.87$
$1.07(1.05-1.09) * 1.07(1.05-1.09) *$

$1.14(1.11-1.18) * 1.1(1.06-1.12) *$

1.03(1.004-1.05)*1 .04(1.01-1.06)*

1.038(0.037) $1.01(0.0102)$

0.2398

0.2348

$2.4 \%$

$5.1 \%$

2268.38

2479.626

$-4510.76$ 